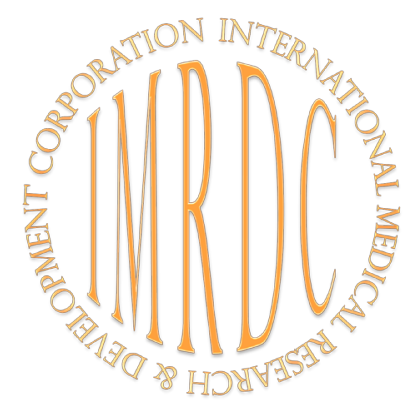

\title{
Prevalence of Otitis Media with Effusion in Children
}

\author{
Nadezhda E. Kuznetsova MD, ScD ${ }^{1,2}$; Ruslan R. Mamedov'; \\ Aygul F. Shcherbakova ${ }^{1}$ \\ ${ }^{1}$ Tyumen State Medical University \\ ${ }^{2}$ Tyumen Region Clinical Hospital №2 \\ Tyumen, the Russian Federation
}

\begin{abstract}
The article presents the prevalence of otitis media with effusion (OME) in children in the Tyumen region. Based on the 12year experience of treating children in a children's regional clinical hospital, it has been established that the children most prone to having OME are pre-school boys (under age 7), and that OME makes up one third of all ear pathologies and accounts for $10.7 \%$ of all treated ENT diseases in children. (International Journal of Biomedicine. 2020;10(1):86-88.)
\end{abstract}

Key Words: otitis media with effusion $\bullet$ radiofrequency myringotomy $\bullet$ tympanostomy tube procedure

\section{Abbreviations}

CT, computed tomography; ENT, Ear, Nose and Throat; OME, otitis media with effusion

\section{Introduction}

Otitis media with effusion (OME) is one of the most widespread and symptomless forms of the clinical course of otitis among children under age 7. OME presents with an accumulation of fluid in the middle ear, which in turn results in conductive and mixed hearing loss. On average about $90 \%$ of children suffer from at least one episode of OME before the age of $7 .^{(1)}$ More than a third of all cases of hearing loss and deafness are associated with the dysfunction of auditory tubes. ${ }^{(2)}$ According to many authors, the main cause for this condition is its obstruction (obturation), which may be caused by the inflammation of auditory tubes, secondary edema, and hypertrophy of nasopharynx and pharynx lymph tissues.

Comprehensive diagnostics of auditory tube dysfunction with 3D computer tomography allows discovering pathologies in the nasal cavity, paranasal sinus and pharynx in $96.3 \%$ of patients. ${ }^{(3,4)}$ The allergy factor and its role in OME development is not conclusive. Allergy processes in the nasal cavity and pharynx may lead to the worsening of auditory tube dysfunction, and, as a result, lead to OME development. ${ }^{(5)}$ Medical sources contain contradictory data on the prevalence of OME in allergic rhinitis among children. ${ }^{(6,7)}$
Gushchin et al., performing medical examinations of children with allergic rhinitis, found OME in $17.9 \%$ of cases. $^{(8)}$ The highest rate $(67.5 \%)$ of OME occurrence was documented among children between the ages of 3 and 6 ; the majority of children with OME $(90.7 \%)$ were diagnosed with secondand third-degree of adenoid hypertrophy with upper-airway obstruction. ${ }^{(9)}$

The aim of this study was to define the prevalence of OME among children according to the data of the ENTdepartment at Tyumen Region Clinical Hospital №2.

\section{Materials and Methods}

Based on these data, 20,000 medical histories were retrospectively analyzed for the period from January 1, 2007 to November 31, 2018. All the children were examined either as scheduled patients or emergency cases with acute or chronic OME who underwent surgical interventions followed by a course of conservative treatment in the postoperative period. A routine check-up of ear, nose and throat was undertaken for all children, as well as otomicroscopy with the LEICA-14 diagnostic microscope, endoscopy of the pharynx, audiometry and tympanometry with an Interacoustics AA222 audiometer 
and an AT235 tympanometer, along with clinical and lab diagnostics, CT of the temporal bone and, if necessary, CT of the paranasal sinus.

Children with acute otitis media who were admitted to a hospital as emergencies underwent a myringotomy under local or general anaesthesia with the aid of a Heine HR binocular loupe. Children with chronic OME (for scheduled operations) received (under an endotracheal anaesthesia and with the help of a LEICA-F40 surgical microscope) one of the following surgical treatments: radiofrequency myringotomy with the Ellman-Russ Surgitron TEE-240 electrode, tympanostomy tube placement with insertion of metal grommets, fluid drainage and transtympanic injection of Fluimucil and Otofa solutions during intra- and postoperative periods for 7 days. After being checked out, all children were referred to regular ENT-specialists, paediatricians, and audiology specialists with a further obligatory audio tympanometry to be done in 3, 6 and 12 months. Results were statistically processed using Microsoft Excel 2007. The study was approved by the Tyumen State Medical University Ethics Committee. Written informed consent was obtained from the child's parents.

\section{Results and Discussion}

A total of 20,000 children with various ENT pathologies were treated over the control period. The estimated percentage of children with otitis was $33 \%$, the rest of the children $(67 \%)$ had other ENT disorders (Figure 1). Among all ear pathologies, one third of the total number of patients was diagnosed with OME (Figure 2).

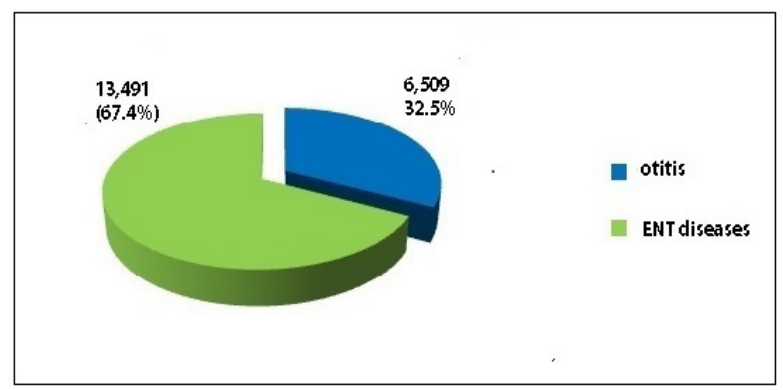

Fig. 1. The prevalence of otitis among ENT diseases.

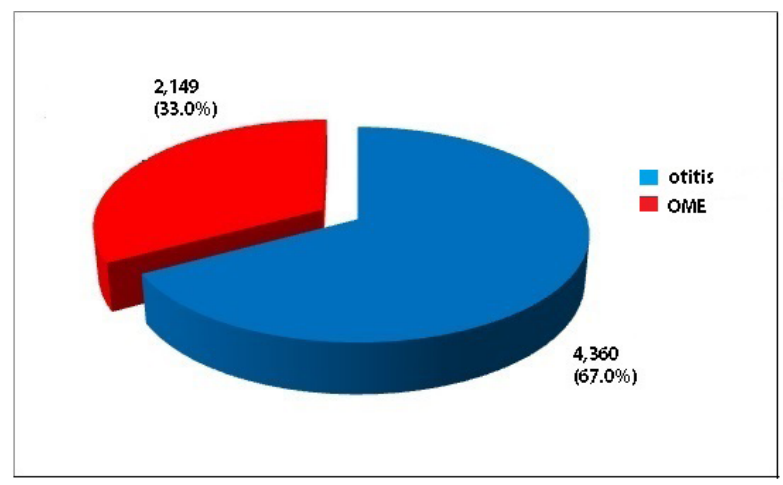

Fig. 2. The prevalence of OME among all ear pathologies.
According to our study, among all patients with ENT diseases treated over the 12-year period from 2007 to 2018, the percentage of children with OME accounted for $10.7 \%$ (Figure 3).

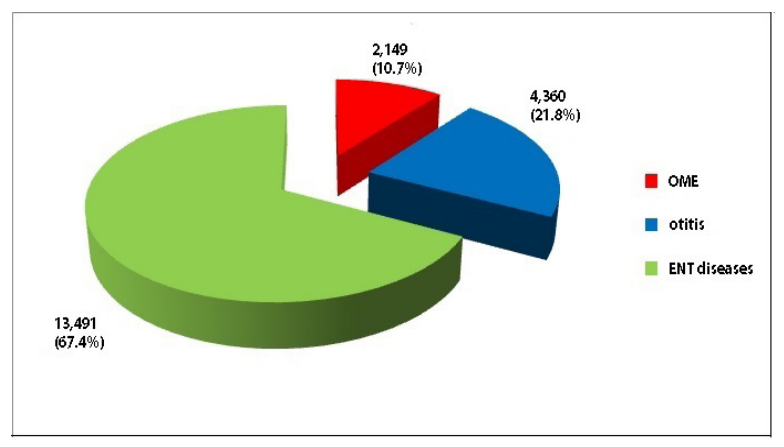

Fig. 3. The prevalence of OME among all ENT diseases.

Among all children with OME, there were 1354(63.0\%) boys and 795(37.0\%) girls. Looking closely at the prevalence of this disorder throughout the year, we can see the following picture: $537(25.0 \%)$ cases in the winter, $507(23.6 \%)$ in the spring, 546(25.4\%) in the summer, and 559(26.0\%) cases in the autumn. Thus, OME is evenly spread over the four seasons with a slight predominance in the autumn. Evaluating the dynamics of the number of OME patients over the years, we found a high prevalence of this pathology with no tendency to decrease. The growth of this ear disorder is more or less stable and is consistent with the rise of other types of otitis among children who undergo treatments at the above-mentioned ENT-department. The prevalence of OME among other types of otitis for the studied years is presented in Figure 4.

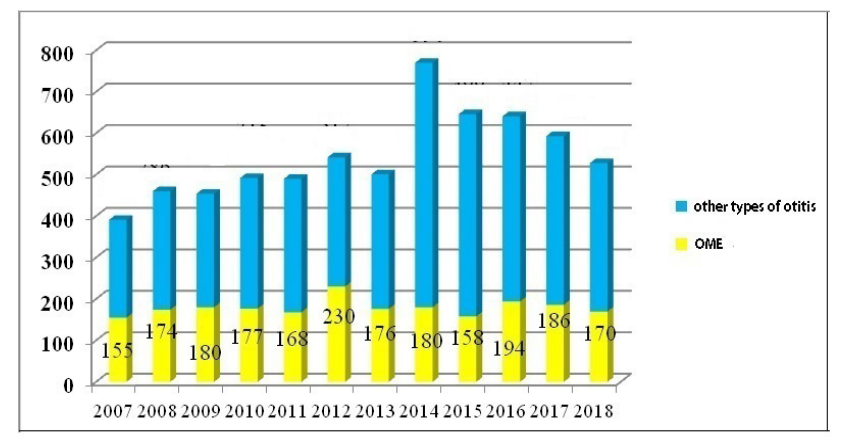

Fig. 4. The prevalence of OME among other types of otitis for the studied years.

OME has been diagnosed in 1133(52.7\%) children in the age group of 3-4 years (mean age of $3.1 \pm 0.03$ years), in $690(32.1 \%$ ) children in the age group of 5-7 years (mean age of $5.88 \pm 0.03$ years), in $249(11.6 \%)$ children in the age group of $8-12$ years (mean age of $9.55 \pm 0.09$ years), and in $77(3.6 \%)$ patients over 12 years of age (mean age of $14 \pm 0.14$ years). Thus, the prevalence of OME among children of prekindergarten age $(52.7 \%)$ and pre-school age $(32.1 \%)$ was predominant. These age groups are at risk for developing 
stable forms of hearing loss and speech disabilities that later may result in difficulties with social adaptation.

In conclusion, the prevalence of OME among children has been quite high (33\% of all ear diseases) for the past 10 years without a downward trend. OME is mainly diagnosed in boys of pre-school age. Equal prevalence of OME in all seasons indicates the relevance of the problem throughout the year.

\section{Competing Interests}

The authors declare that they have no competing interests.

\section{References}

1. Bogomil'sky MR. [Children's otorhinolaryngology in Russia - realities, problems and prospects]. Bulletin of Otorhinolaryngology. 2006;(1):4-7. [Article in Russian].

2. Kuznetsova NE. Radiofrequency myringotomy and endoscopic adenoidectomy for otitis media with effusion in children. Abstract of PhD Thesis. Moscow; 2013. [In Russian].
3. Krasnozhen VN, Lithuanian TS. [Value of a comprehensive diagnostics in patients with dysfunction of the auditory tubes]. Russian Rhinology. 2013;21(2):22. [Article in Russian].

4. Krasnozhen VN, Andreeva IG, Tokarev PV. [The treatment of exudative otitis media in children]. Russian Otorhinolaryngology. 2018;96(5):115-122. [Article in Russian]. 5. Döner F, Yariktas M, Demirci M.The role of allergy in recurrent otitis media with effusion. J Investig Allergol Clin Immunol. 2004;14(2):154-8.

6. Shamova AG, Gomzina EG. Prevalence of combined forms of allergic rhinitis in high-school-age children. The IV Russian Congress "Modern technologies in pediatrics and pediatric surgery". Moscow, 2005: 31. [In Russian].

7. Malo JL. Occupational rhinitis and asthma due to metal salts. Allergy 2005; 60(2):138-9.

8. Gushchin IS, Ilyina NI, Polner SA. Allergic rhinitis. Manual for doctors. M., 2002. [In Russian].

9. Roschektaeva Yu. A. Prevalence, features of the clinical course and effectiveness of the surgical treatment of otitis media with effusion in children: Abstract of $\mathrm{PhD}$ Thesis. Moscow; 2015. [In Russian]. 